\title{
The Allowance Mechanism of China's Carbon Trading Pilots: A Comparative Analysis with Schemes in EU and California*
}

\author{
Ling Xiong ${ }^{\mathrm{a}, \mathrm{c}}$, Bo Shen ${ }^{\mathrm{b}} \uparrow$, Shaozhou Qi ${ }^{\mathrm{c}}$, Lynn Price $^{\mathrm{b}}$, Bin Ye ${ }^{\mathrm{d}}$ \\ ${ }^{a}$ Institute for International Studies, CICTSMR, Wuhan University, Wuhan Hubei 430072, China \\ ${ }^{b}$ China Energy Group, Lawrence Berkeley National Laboratory, Berkeley CA 94720, USA \\ ${ }^{c}$ Climate Change and Energy Economics Study Center, Wuhan University, Wuhan Hubei 430072, China \\ ${ }^{d}$ Research Center on Modern Logistics, Graduate School at Shenzhen, Tsinghua University, Shenzhen 518055, China
}

\begin{abstract}
The allowance mechanism is one of the core and sensitive aspects in the design of a carbon emissions trading scheme and affects the compliance cost for each entity covered under the scheme. By examining China's allowance mechanism from two aspects-allowance allocation and allowance distribution, this paper compares China's carbon trading pilots with the EU Emissions Trading Scheme and California Cap-and-Trade Program. The comparison identifies the unique features in allowance mechanism and particular issues that affect the efficiency of the pilots. The paper also recommends courses of action to strengthen China's existing pilots and to build valuable experiences for the establishment of the national cap-and-trade system in China.
\end{abstract}

Keywords: China carbon trading pilot; cap-and-trade; ETS; allowance allocation; climate change

\section{Introduction}

Due to its rapid economic expansion over the last decade, China has become the world's largest energy consumer and greenhouse gas (GHG) emitter. With growing resources and environmental constraints domestically and the need to meet international commitments for GHG emissions abatement, China's National Development and Reform Commission (NDRC) launched a series of local carbon emissions trading pilots in seven provinces and cities including Shenzhen, Beijing, Tianjin, Shanghai, Chongqing, Guangdong, and Hubei [1], which started operation between 2013 and 2014.

The world's oldest carbon trading scheme is the European Union Emission Trading System (EU ETS), which came into effect in 2005. One of the most widely debated aspects of the EU ETS has been the emissions allowances mechanism for covered installations. Sijm et al. [2] has pointed out that where companies pass on the opportunity costs of pollution licenses into consumer prices, $100 \%$ free allocation leads to windfall profits for polluting industry. Benz et al. [3] has argued that a higher share of initial auctioning is better for aggregate welfare, because it pre-empts rent-seeking lobbying costs over the initial division of allowances. Furthermore, Pahle et al. [4] and Golombek et al. [5] have found that the combination of grandfathering and windfall profits in the power sector was distortionary for investments in new power plant capacity. For the decentralized National Allocation Plan (NAP) approach in Phases 1 and 2 of EU ETS, free allocation methodologies under the NAPs were also found to be poorly harmonized across EU due to the high degree of discretion exercised by its Member States [6]. Sartor et al. [7] provided an analysis of the new allocation rules based on historical production multiplied by benchmarks in Phase 3, which showed that the new rules had reduced the scope for windfall gains by participating firms in EU ETS while also effectively mitigating carbon leakage risks.

California's Cap-and-Trade program(CA CAT) is the only economy-wide carbon trading scheme to be enacted so far in the US and is set to become the world's second largest carbon market behind the EU ETS [8]. Shen et al. [9] reviewed the Californian scheme and drew insights for China's pilots from various perspectives including the legal basis, institutional arrangement, program structure and allowance mechanism. Zuckerman et al.[10] identified barriers to cost-effective abatement by industrial firms under the Cap and Trade Program in California, and policy levers that could address those barriers. Schmalensee and Stavins [11] examined the design and performance of California's Cap-and

\footnotetext{
* This paper was presented at the 7th International Conference on Applied Energy (ICAE2015), March 28-31, 2015, Abu Dhabi, UAE (Original paper title: " Assessment of Allowance Mechanism in China's Carbon Trading Pilots" and Paper No.: 723).

$\dagger$ Corresponding author at: China Energy Group, Lawrence Berkeley National Laboratory. Tel.: +1-510-495-2991 ; E-mail address: BoShen@lbl.gov

Authors E-mail address: xiong12004@126.com (Ling Xiong); cneuus@126.com (Shaozhou Qi); LKPrice@lbl.gov (Lynn Price); ye.bin@sz.tsinghua.edu.cn (Bin Ye).
} 
-Trade system and argued that the system has demonstrated that an initial free allowance allocation aimed at fostering political support can be successfully transitioned over time to greater auctioning of allowances.

The design of the Chinese carbon trading pilots has been studied by a number of researchers. Han et al. [12] and Lo [13] assessed the preparation of the pilots and argued that due to the great difficulties and large scale there would be a tremendous challenges, both practically and theoretically, for the emissions trading in China. Jotzo and Löschel [14], Zhang et al. [15], and Liu et al. [16] conducted a general assessment of China's seven carbon trading pilots, while several other researchers examined specific pilots including their institutional structures and design features, such as Jiang et al. [17] for Shenzhen, Wu et al. [18] and Liao et al. [19] for Shanghai, and Qi et al. [20] for Hubei. To investigate the impact of carbon allowance rules, Zhang et al. [21] used the multi-stage profit model and proposed that under the rules of grandfathering, enterprises covered by an ETS may maximize current profits; however, under the rule of benchmarking, those enterprises may care more about the effect of current decisions on the future profits. Tang et al. [22] formulated a multi-agent-based model and argued that the grandfathering rule is relatively moderate, while the benchmarking rule is more aggressive. To further discuss the issues about China's national carbon market, Zhou et al. [23] and Cui et al. [24] have constructed an interprovincial carbon emissions trading model to evaluate its economic performance and the cost-saving effects. Hong et al. [25] developed a decision support model for establishing benchmarks as a tool for free allocation in the construction industry, and Xu et al. [26] proposed an alternative method derived from Boltzmann distribution to estimate the allowances in the power generation industry.

Except for Pang and Duan [27], the existing literature has seldom focused on the design details of the allowance mechanism in China's pilots. Despite a detailed introduction to the methods for allowance allocation adopted by the pilots, Pang and Duan [27] has neither made a comparison with allowance allocation strategies in the international trading schemes nor given a discussion in pointing out the problems and challenges facing China's pilots. As one of the core components in a carbon trading scheme, however, the allowance mechanism affects the compliance responsibility and cost of each covered entity. It is always the most sensitive topic that attracts great attention from the research community, policy makers, and covered entities. Therefore, this paper sets to address the gap by conducting a comprehensive and in-depth analysis of the allowance mechanism in China's carbon trading pilots. Through comparing China's pilots with EU ETS and CA CAT, our analysis will focus on allowance cap, allowance composition, allowance allocation method, and distribution and dynamic management of allowances.

This paper is organized as follows. In Section 2, we summarize the analysis framework and methodology used in this study on allowance mechanism of China's seven ETS pilots. In Section 3, we provide a comparative analysis of the allowance allocation mechanism of the China's ETS pilots with EU ETS and CA CAT. In Section 4, we examine the allowance distribution mechanism of the China's ETS pilots. In Section 5, we discuss some key issues facing the allowance mechanism of China's pilots and provide a set of recommendations. The conclusions are given in Section 6.

\section{Framework and methodology}

The analysis of the allowances mechanism of China's carbon trading pilots focuses on two aspects the allowance allocation and distribution of allowances. The allowance allocation determines how the total emission cap and composition of emission allowances is set and how emission allowances under the total cap are calculated for covered entities. The distribution of allowances deals with the allotment of calculated allowances to participating entities and the dynamic management of these allowances in the post-distribution period. They are the two essential and interconnected parts of the carbon allowance system. In this study, we compare the allowance systems in terms of both allowance allocation and distribution in China's pilots with those in EU ETS and CA CAT. Figure 1 shows the analytical framework we developed to guide the analysis of the carbon allowance mechanism in China ETS pilots. 


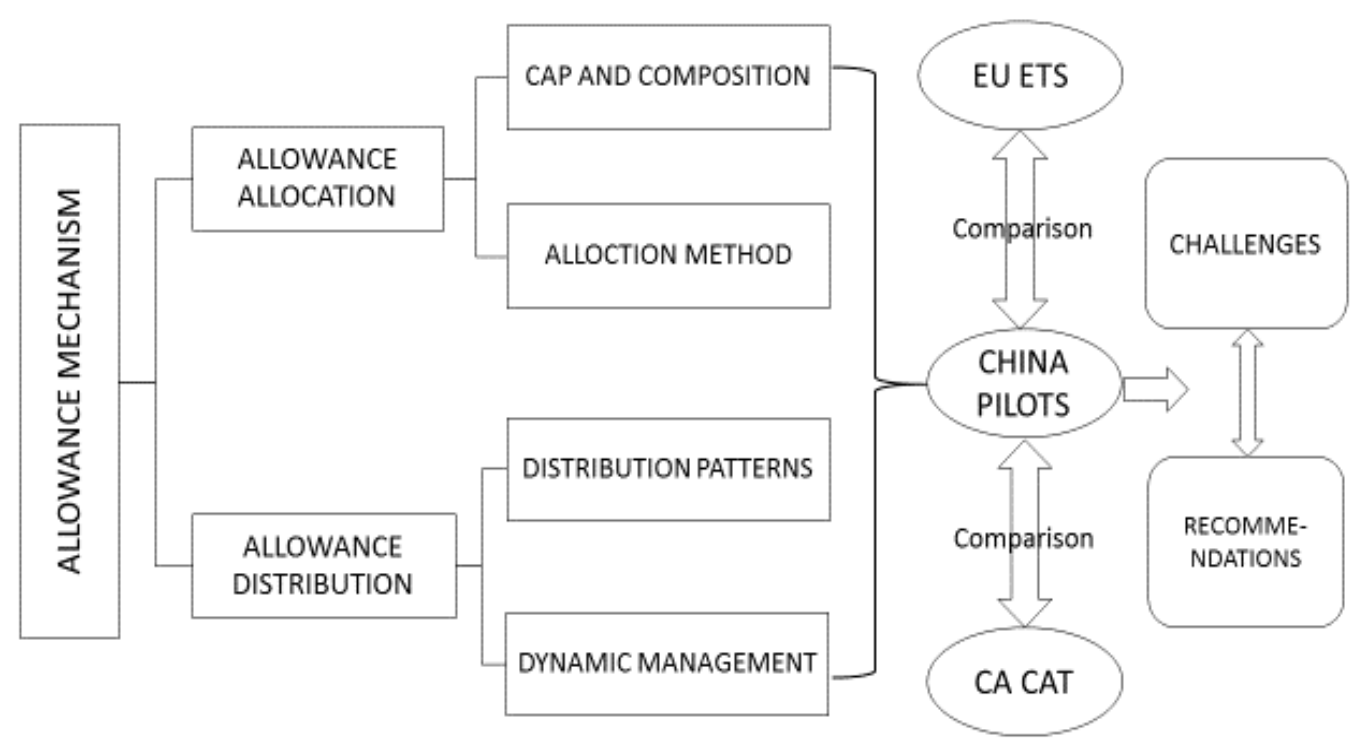

Fig.1. Analytical framework for comparative analysis of the allowance mechanism in China ETS pilots

Our analysis is based on the information we obtained from the government documents, research literature and expert interviews. The government documents include the EU directives and related explanatory documents about the EU ETS, the California state law and Air Resource Board files posted at its web-site on the cap-and-trade scheme, and the China's NDRC regulations and local DRC administrative measures governing seven carbon trading pilots. In addition to the desk-top research, we conducted 25 in-person interviews with policy makers and emission-trading experts from the EU, California, and China pilot provinces and cities. The interviewees include four experts at the California Air Resource Board (CARB), two policy officers at Directorate-General for Climate Action of European commission, two managing consultants at ECOFYS and two consultants at the Center for Clean Air Policy (CCAP), two policy officers at DRC of China's Hubei Province, two managing experts at Hubei Emission Exchange, two researchers at Tsinghua University in Beijing, one policy officer at DRC and two managing experts at Environment and Energy Exchange in Shanghai, one policy officer at DRC and one researcher at Guangzhou Energy Strategy Research Center in Guangdong, one researcher and one managing expert at Tianjin Emission Exchange, one managing expert at Shenzhen Emission Exchange, and one managing expert at Chongqing United Assets and Equity Exchange Group. The interview for CARB experts was conducted when the authors visited CARB, and the interviews for EU, ECOFYS and CCAP experts were conducted during their visit in Beijing and Hubei. For the expert interview of China's carbon trading pilots, it was conducted when the experts visited Hubei or authors visited the pilot.

\section{Comparative analysis of allowance allocation between EU ETS,CA CAT and China's pilots}

\subsection{Comparative analysis of emission caps and composition of allowances}

\subsubsection{The emission caps and composition of allowances in EU ETS and CA CAT}

The EU ETS has decreasing total emissions caps over its three phases. From the first (2005-2007) phase to the second (2008-2012), the total cap declines from 2,181 million allowances to 2,083 million per year [28]. Starting from phase 3 (2013-2020), the cap decreases each year by $1.74 \%$ of the average total quantity of allowances issued annually in 2008-2012 to 1,720 million allowances in 2020 [29].In the EU ETS, there are two types of allowances being allocated: one for the existing facilities and the other for new capacity. 
Similar to the EU ETS, the CA CAT also has declining emissions caps over time at pre-determined rates for the covered entities ${ }^{\ddagger}$, which are set at about $2 \%$ below the emission level of the previous year in the initial compliance period (2012-2014) and at 3\% annually for the second (2015-2017) and third (2018-2020) compliance periods [30]. In the three separate compliance periods in the CA CAT, the total allowance caps are set at 488 million, 1,147 million, and 1,039 million allowances, respectively [31]. Different from EU ETS, the CA CAT set aside a certain number of allowances serving as the allowance price containment reserve to ensure that the auction prices for allowances are kept in an acceptable range.

\subsubsection{Comparative analysis of emission caps and composition of allowances in China's pilots}

136

137

138

139

140

141

142

143

144

145

146

147

148

149

150

151

152

153

154

155

156

In China, caps and allowance compositions are quite different among different pilots due to the various economic structures of these provinces and cities. As shown in Figure 2, in 2013 the local emission cap ranges from the lowest of 33 million tonnes in Shenzhen to the highest of 388 million tonnes in Guangdong [32]. In spite of smallest cap, however, the scale of 635 covered entities in Shenzhen is much greater than that of 184 covered entities in Guangdong. This reflects the significant difference in economic structures: Shenzhen's economy is largely service oriented while the economy in Guangdong relies heavily on energy-intensive heavy industry that emits a large amount of carbon dioxide. Over the same pilot period (2013-2015), caps in Beijing, Shanghai, Tianjin, and Shenzhen have been designed to remain unchanged while Guangdong has increased the cap from 388 million to 408 million tonnes to allow industrial facilities to increase their product [33], Hubei has decreased the cap from 324 million to 281 million tonnes to adapt to the changing economic growth [34], and Chongqing would reduce its cap by $4.13 \%$ per year [35]. Figure 2 shows the respective caps and numbers of covered entities in China's seven carbon trading pilots.

In a developing economy like China, carbon trading pilots are designed differently than the EU ETS and CA CAT and have taken into consideration the local needs for economic expansion and industrialization. As a result, Beijing, Shenzhen, Guangdong, and Hubei have divided their allowances into three parts including separate quotas respectively for existing facilities, production expansion, and for potential adjustment, and Shanghai and Tianjin divides the allowances allocation into existing facilities and new production. Only in Chongqing, all allowances are allocated to existing facilities with no consideration for production expansion.

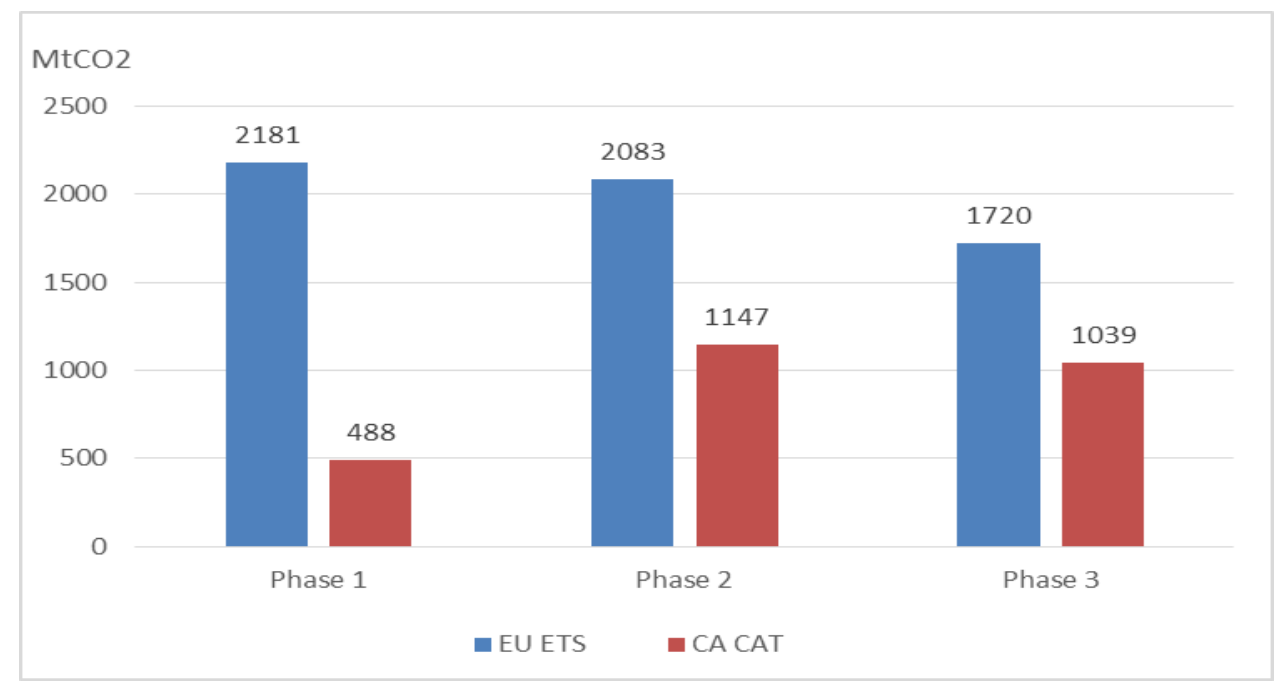

Source: Ellerman et al. (2010), EC (2009,2012), CARB (2010,2011).

Fig. 2. The declining caps of the EU ETS and the CA CAT

\footnotetext{
* In China's pilots, entities subject to emission caps are called enterprises while these entities are called installations in CA and EU ETS. In this paper, we use the name "covered entities" in referring to the entities subject to emission caps.
} 


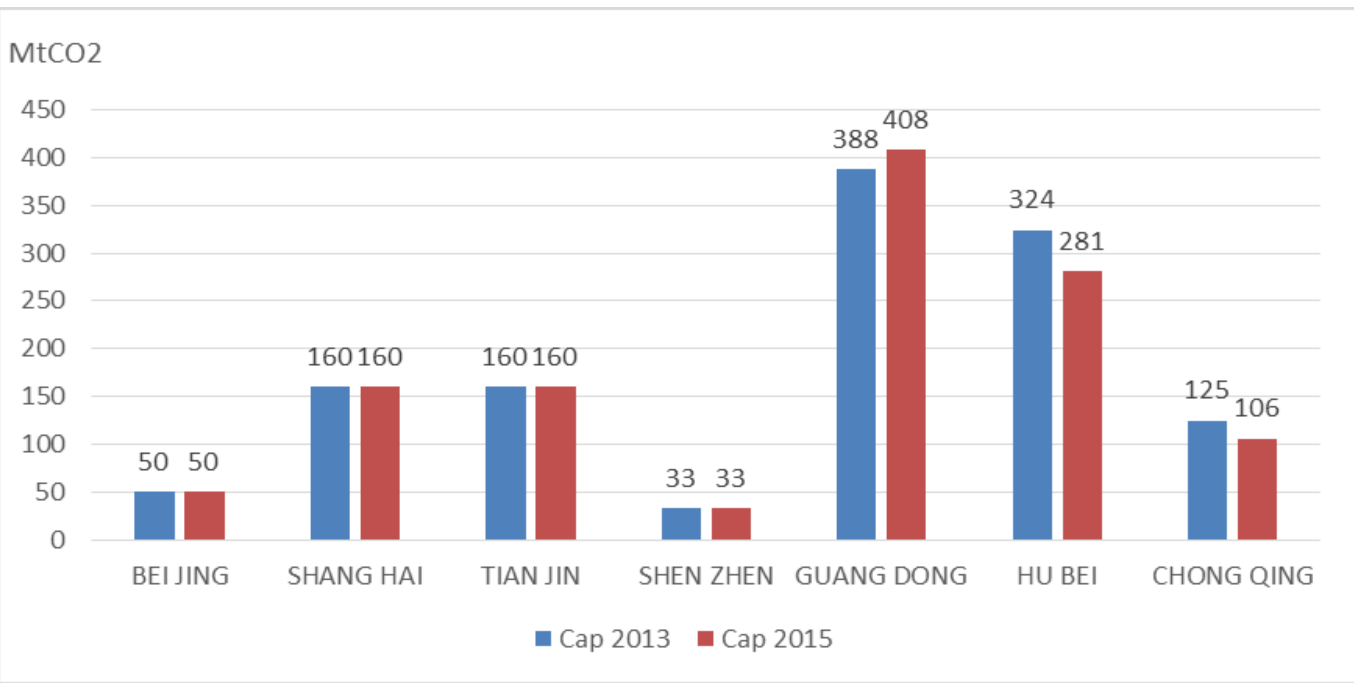

Source: China's carbon trading pilots management rules and allocation plans and SinoCarbon (2014).

Fig. 3. The Caps of China's carbon trading pilots in 2013 and 2015

\subsection{Comparative analysis of allowance allocation methods}

\subsubsection{The allowance allocation methods in EU ETS and CA CAT}

During the initial implementation of EU ETS, allowance allocation was conducted mainly based on a grandfathering rule, focusing on historical emissions from existing facilities due to issues such as data availability and political feasibility [28]. With the development of the trading scheme and accumulation of emissions data, however, the EU ETS has switched its allocation method to using benchmarks in the third phase and established a benchmarking system that includes 52 types of product benchmarks and various benchmarks for fuels, heat, and production processes. The allowances allocated to each installation for each of its eligible products are determined by four elements: product benchmark, historical production, carbon leakage factor, and cap adjustment factor. The basic formula can be summarized as follows [36]:

$F A_{i, p, t}=B M_{p} \times H A L_{i, p} \times C L E F_{p, t} \times C S C F_{t}$

Where $F A_{i, p, t}$ is the total free allocation that entity $i$ receives for its product $p$ in year $t . B M_{p}$ is the product emissions-intensity benchmark for product $p$. It is generally measured in tonnes of $\mathrm{CO}_{2}$ per unit of output, and is based on the average emissions intensity of the $10 \%$ most efficient facilitates in the EU ETS in 2007-08 [37]. If there is no corresponding product benchmark available, a fallback methodology is used as an alternative [38]. $H A L_{i, p}$ is the reference historical activity (production) level of product $p$ by entity $i$, and the entity is allowed to choose the highest value of the 2005-08 and 2009-10 medians. $C L E F_{p, t}$ in formula (1) is an allocation reduction factor that is applied to a small minority of products that are not considered to be at risk of carbon leakage, and $C S C F_{t}$ is a uniform, cross-sectoral correction factor that can be applied to ensure that the total free allocation will not exceed the maximum annual amount of free allocation as defined.

In the CA CAT, allowance allocation adopts the benchmarking approach with a benchmark system that consists of 28 different types of products and three fallback benchmark values [31]. For the covered facilities under the CA CAT, the number of allowances is allocated based on the consideration of the following factors: benchmark, three-year moving average output, industrial leakage factor, and cap decline factor. The basic equation for allocation based on product-based benchmarks can be summarized as follows ..

$$
A_{t}=\sum_{a=1}^{n} B_{a} \times \text { Output }_{a, t} \times A F_{I, t} \times c_{t}
$$

Where $A_{t}$ is the number of allowances a covered entity will receive in a given year. In equation (2), the $B_{a}$ term is the benchmark based on $90 \%$ of weighted average or best-in-class emission intensity level for each production activity, which remains fixed in time. The Output $t_{a, t}$ term is an annually-updated three-year moving average of product output for each activity. The assistance factor, $A F_{I, t}$ is assigned based on an industry's leakage risk. The cap decline factor, $c_{t}$ reflects the decreasing total level of allowances available over time relative to the initial 2012 narrow-scope cap [31]. Unlike the EU ETS, 
the fallback method in the CA CAT is based on energy (electricity, fuel, and heat) rather than the production processes.

To sum up, through establishing their respective benchmarking systems, the EU and California not only provide fair incentives for cutting greenhouse gases emissions and encouraging energy efficiency improvement, but also effectively protect their industry threatened by international competition. Comparatively speaking, the benchmarking systems of CA CAT is more stringent than that of EU ETS.

\subsubsection{Comparative analysis of the allowance allocation methods in China's pilots}

(1) Beijing and Tianjin pilots: historical emissions + historical carbon intensity + industrial benchmarks

As shown in Table 1, Beijing and Tianjin adopt a method that combines historical emissions, historical carbon intensity, and industrial benchmarks. In northern China, the facilities that provide electricity and heating are very important for household winter heating, and the quantity of output cannot independently be determined by the covered entities. Therefore, Beijing and Tianjin pilots utilize a unique method of "historical average carbon intensity" to allocate allowances for the industry [39][40].

On the one side, this method of considering of historical carbon intensity can ensure that the facilities that provide electricity and heating remain stable and accountable, because the allowances allocated to them are dependent on their own historical average carbon intensity multiplied by actual supply. On the other side, the method is designed to encourage enterprises to at least keep or reduce their carbon intensity to avoid additional emission cost. For the existing facilities and new entrants in sectors other than providing electricity and heat in Beijing and Tianjin, the historical emissions and industrial benchmarks are considered to allocate allowances.

(2) Shanghai pilot: historical emissions + industrial benchmarks + early abatement incentive + rolling baseline year

By considering early abatement incentives, the Shanghai pilot has made an adjustment to the pure grandfathering based on historical emissions to allow early movers on reducing carbon emissions to receive credits for their efforts. Moreover, the Shanghai pilot has also adopted a "rolling baseline year" to allow enterprises to use the latest year's data if emissions increased over 50\% from 2009 to 2011 to calculate their allowances [41]. These adjustments are designed to make allowances allocation fairer and more realistic. In Shanghai pilot, the benchmarking is utilized for allowances allocation in the industry with a single product or business, such as power production as well as aviation, airport and port because it is relatively easy to set the benchmark. However, one difference from EU ETS or CA CAT is that the Shanghai pilot has divided the power generators into six types by setting a corresponding benchmark for each one.

(3) Guangdong and Hubei pilots: historical emissions + industrial benchmarks + rolling baseline year

Similar to the Shanghai pilot, Guangdong and Hubei pilots combine historical emissions with a rolling baseline year and industrial benchmarks but do not have the early abatement incentives like what Shanghai does. However, the industrial benchmarking is only applied in certain industrial process. For example, in the Guangdong pilot, allowances for the cement clinker production and cement grinding process are calculated by using benchmarking, while allowances allocated for cement mining and another grinding process is allocated by historical emissions methodology [42]. As for the power production in the Hubei pilot, allowances are divided into two categories. One consists of the pre-distribution allowances, which are equal to the $50 \%$ of the historical emissions after adjustment using a total adjustment factor and another is the adjusted allowances that are allocated to the power producers that generate more than the pre-distribution [43]. Pre-distribution allowances are determined using the historical emissions method while the calculation of adjusted allowances is based on the industrial benchmarking. 
Table 1

249 Comparison of allocation methods in China's carbon trading pilots, EU ETS and CA CAT

\begin{tabular}{|c|c|c|c|c|c|c|}
\hline \multirow[b]{2}{*}{ Region } & \multicolumn{2}{|c|}{ Historical emissions } & \multicolumn{2}{|c|}{ Historical intensity } & \multicolumn{2}{|c|}{ Benchmarking } \\
\hline & Coverage & $\begin{array}{l}\text { Allocation } \\
\text { formula }\end{array}$ & Coverage & Allocation formula & Coverage & Allocation formula \\
\hline $\begin{array}{l}\text { BEI } \\
\text { JING }\end{array}$ & $\begin{array}{l}\text { existing facilities of } \\
\text { manufacturing, other } \\
\text { industrial and service } \\
\text { sectors }\end{array}$ & $\begin{array}{l}\text { historical average } \\
\text { emissions } \times \text { decline } \\
\text { coefficient }\end{array}$ & $\begin{array}{l}\text { existing } \\
\text { facilities in } \\
\text { electricity } \\
\text { and heat }\end{array}$ & $\begin{array}{l}\text { historical average } \\
\text { carbon intensity } \times \\
\text { power (or heat) supply } \\
\times \text { decline coefficient }\end{array}$ & $\begin{array}{l}\text { new production of } \\
\text { the covered } \\
\text { industries }\end{array}$ & $\begin{array}{l}\text { Industrial benchmark } \times \\
\text { output }\end{array}$ \\
\hline $\begin{array}{l}\text { SHANG } \\
\text { HAI }\end{array}$ & $\begin{array}{l}\text { industrial sectors other } \\
\text { than electricity; shopping } \\
\text { malls, hotels, commercial } \\
\text { buildings, and railway } \\
\text { station }\end{array}$ & $\begin{array}{l}\text { historical emissions } \\
\text { base }+ \text { early } \\
\text { abatement incentives }\end{array}$ & none & none & $\begin{array}{l}\text { electricity, } \\
\text { aviation, airport and } \\
\text { port sectors }\end{array}$ & $\begin{array}{l}\text { Industrial benchmark } \\
\times \text { generated electricity } \\
\times \text { load correction factor; } \\
\text { Industrial benchmark } \\
\text { ×business volume+ early } \\
\text { abatement incentives }\end{array}$ \\
\hline $\begin{array}{l}\text { TIAN } \\
\text { JIN }\end{array}$ & $\begin{array}{l}\text { existing facilities of iron } \\
\& \text { steel, chemical, } \\
\text { petrochemical, oil and gas } \\
\text { extraction }\end{array}$ & $\begin{array}{l}\text { historical emissions } \\
\text { base } \times \text { performance } \\
\text { coefficient } \times \\
\text { industrial emission } \\
\text { control factor } \\
\end{array}$ & $\begin{array}{l}\text { existing } \\
\text { facilities in } \\
\text { electricity } \\
\text { and heat }\end{array}$ & $\begin{array}{l}\text { historical average } \\
\text { carbon emissions of } \\
\text { per unit power (or } \\
\text { heat) } \times \text { power supply } \\
\text { (or heat) }\end{array}$ & $\begin{array}{l}\text { new production of } \\
\text { the covered } \\
\text { industries }\end{array}$ & $\begin{array}{l}\text { Industrial benchmark } \times \\
\text { output }\end{array}$ \\
\hline $\begin{array}{l}\text { CHONG } \\
\text { QING }\end{array}$ & $\begin{array}{l}\text { Aluminum, metal alloys, } \\
\text { calcium carbide, cement, } \\
\text { steel, caustic soda }\end{array}$ & $\begin{array}{l}\text { the highest of } \\
\text { historical annual } \\
\text { emissions }\end{array}$ & none & none & none & none \\
\hline $\begin{array}{l}\text { SHEN } \\
\text { ZHEN }\end{array}$ & none & none & none & none & $\begin{array}{l}\text { electricity, water, } \\
\text { gas, construction } \\
\text { and manufacturing }\end{array}$ & $\begin{array}{l}\text { Industrial benchmark } \times \\
\text { output }\end{array}$ \\
\hline $\begin{array}{l}\text { GUANG } \\
\text { DONG }\end{array}$ & $\begin{array}{l}\text { cogeneration, cement } \\
\text { mining and other grinding } \\
\text { processes, petrochemical, } \\
\text { short process steel }\end{array}$ & $\begin{array}{l}\text { historical average } \\
\text { emissions } \times \text { decline } \\
\text { coefficient }\end{array}$ & none & none & $\begin{array}{l}\text { pure power } \\
\text { generation, cement } \\
\text { clinker production } \\
\text { and grinding } \\
\text { process, long } \\
\text { process steel }\end{array}$ & $\begin{array}{l}\text { benchmark } \times \text { historical } \\
\text { average output } \times \text { decline } \\
\text { coefficient }\end{array}$ \\
\hline $\begin{array}{l}\text { HU } \\
\text { BEI }\end{array}$ & $\begin{array}{l}\text { pre-allocated quota of } \\
\text { power enterprises; } \\
\text { industrial enterprises }\end{array}$ & $\begin{array}{l}\text { historical emissions } \\
\text { base } \times \text { cap adjustment } \\
\text { factor }\end{array}$ & none & none & $\begin{array}{l}\text { ex-post adjustment } \\
\text { quotas of electricity } \\
\text { producers }\end{array}$ & $\begin{array}{l}\text { Industrial benchmark } \times \\
\text { excess or shortage of } \\
\text { generated electricity }\end{array}$ \\
\hline $\begin{array}{l}\text { EU ETS } \\
\text { Phase3 }\end{array}$ & none & none & none & none & $\begin{array}{l}\text { electricity, paper, } \\
\text { petrochemical, iron } \\
\text { and steel, building } \\
\text { materials, } \\
\text { chemicals, aviation, } \\
\text { aluminum } \\
\end{array}$ & $\begin{array}{l}\text { Product benchmark } \times \\
\text { median of historical } \\
\text { production } \times \\
\text { carbon leakage factor } \\
\text { xcap adjustment factor }\end{array}$ \\
\hline CA CAT & none & none & none & none & $\begin{array}{l}\text { electricity, oil } \\
\text { refining, oil and gas, } \\
\text { glass, food } \\
\text { processing, cement } \\
\text { transportation }\end{array}$ & $\begin{array}{l}\text { Product benchmark } \times \\
\text { three-year moving } \\
\text { average output } \times \\
\text { industrial leakage factor } \\
\times \text { cap decline factor }\end{array}$ \\
\hline
\end{tabular}

250 Source: Ecofys (2009), EC (2011,2012), CARB (2010,2011), SinoCarbon (2014) and China's carbon trading pilots' management

$251 \quad$ rules and allocation plans.

252 (4) Shenzhen pilot: multi-round game + industrial benchmarking

Compared with EU ETS, CA CAT, and the other six pilots in China, the Shenzhen pilot has taken a

254 different approach in allocating the allowances. Shenzhen combines the multi-round game and 255 industrial benchmarking, and utilizes the first method in allocating free allowances to manufacturing 256 enterprises while applying the benchmarking to power and water supply companies [44]. For the 257 manufacturing industry, due largely to a large number of sub-sectors covered by the emissions trading 258 and their big production fluctuation, it is rather difficult for the pilot administration to predict the 259 changes in allowances for meeting the future needs of the enterprises, thus, Shenzhen has designed the 260 multi-round game among participating enterprises to allocate allowances Through the effective design 261 of collective restriction rule, the stimulus and punishment rule, and the information communication 262 mechanism, the pilot administrator can ensure the realization of the carbon emission and carbon 263 intensity reduction targets, and simultaneously encourage covered entities to tell the truth about their 264 carbon emissions and outputs [45]. 
In the Chongqing pilot, the administrator upholds a fairly liberal view that enterprises know their own emissions best, and the government should minimize the intervention to the enterprise. Thus, Chongqing allocates the allowances through self-declaration by enterprises in which the individual amount of allowances is requested by the enterprise itself, while the government is responsible for controlling the total annual allowances (the cap) initially set at the highest total annual emissions of covered entities in 2008-2012 and making the total number of allowances shrinking by $4.13 \%$ per year through 2015. Although the self-declaration provides the covered entities with significant freedom, the approach can create morel risks that the dishonest will gain in the cost of honest enterprises. It could also prevent from building a dynamitic trading scheme and creating right carbon prices.

Seven China's pilots have designed various approaches in allocating their allowances. When designing their methods, these pilots have to balance various considerations including continuing economic growth, fast industrial transition, competitiveness, and control of carbon emissions. In the lack of both preparation time and sufficient and reliable emissions data, China's carbon trading pilots mainly rely on historical emissions and carbon intensity with limited benchmarking in allocating their allowances. From the perspective of fairness and achieving emissions reduction, the Shanghai pilot is better than other pilots in terms of allocation. Compared to EU ETS and CA CAT, however, the number of sectors and entities affected by benchmarking in the Shanghai pilot is rather small, and the stringency of the benchmarks needs to be improved.

\section{Comparative analysis of allowance distribution between EU ETS ,CA CAT and China's pilots}

\subsection{Comparative analysis of allowance distribution}

\subsubsection{Allowance distribution in EU ETS and CA CAT}

In the EU ETS, allowances are distributed to covered entities mainly through free distribution and competitive auction. In its initial phases, in order to attract enterprises to actively participate in the trading system, the EU primarily employed free distribution that accounted for over $95 \%$ of the total allowances, while the proportion of competitive auction was below 5\% [28]. Starting in the second phase, the proportion of the auction had increased, but is still limited to $10 \%$. The problem with free distribution is obvious and serious. It allows certain business such as power generation companies to obtain a large number of "windfall" gains. Therefore, from the third phase, the European Commission made a change to auction at least $50 \%$ of the total permits in sectors other than the energy industry in which permits were obtained 100\% through the auction in 2013 [46].

In the CA CAT, its allowance distribution is a combination of free distribution, auction, and fixed price sale. Most Californian industrial facilities received free allowances in the initial stage, but the proportion of the subsequent free allowances will vary across difference industries depending on the degree of carbon leakage risk in different sectors. For example, high-risk industries will receive 100\% free allowances in all three compliance periods while the middle-risk and low-risk sectors will receive a descending number of free allowances [31], as shown in Table 2. On the contrary, the proportion of the allowances to be auctioned will continue to rise. CA CAT is quite unique in auctioning allowances. There are three types of auction including current allowances auction, advance allowances auction, and consignment auction. In addition, CA CAT also sets aside a number of allowances to create an Allowance Price Containment Reserve that can be offered through reserve sales at a set price that is adjusted annually with a $5 \%$ increase plus inflation. 
Similar to the CA CAT, China's carbon trading pilots in Beijing, Shenzhen, and Hubei utilize a mixed approach to distribute their allowances, but the proportion of free distribution in these pilots are no less than $90 \%$. Furthermore, Beijing has set aside up to $5 \%$ of total annual allowances as a reserve which is distributed through an auction or fix price sale in order to stabilize the carbon trading prices [47]; Shenzhen stipulates that the allowances distributed by auction should not be less than $3 \%$ of total annual allowances and the reserve allowances must be sold at a set price [44]; Hubei reserves no more than $10 \%$ of the total annual allowances, of which $3 \%$ are used for price discovery by public auction and the rest are used for stabilizing the market through fix price sale [48], as shown in Table 2. Despite the very small number of allowances distributed with auction or sale, the objective is to give pilot administrators the means and flexibility in making necessary adjustment to the carbon trading markets.

\section{(2) Guangdong pilot: free distribution + auction}

Similar to the EU ETS, the Guangdong pilot has instituted a combination of free distribution and auction. In encouraging covered entities to actively participate in its carbon trading and pursuing energy-saving retrofits and emissions reduction, Guangdong has placed a mandate requiring that in the first year of compliance (2013-2014), all covered entities would not receive their $97 \%$ of allocated free allowances until they completed $3 \%$ of auctioned allowances [42]. In addition, the reserve allowances set for stabilizing the trading market will only be distributed through an auction.

(3) Shanghai, Tianjin, and Chongqing pilots: complete free distribution

In Shanghai, Tianjin, and Chongqing pilots, allowances are distributed to the covered entities completely free. For Shanghai, in the period from 2013 to 2015 all allowances will be freely distributed in one round, but future allowances will be auctioned at an unspecified later time. For Tianjin, although allowance distribution such as auctioning is in the plan document over time, during the pilot period however all allowances would be distributed completely free. In the Chongqing pilot, there are no other plans other than free distribution.

In order to establish the initial carbon market and attract enterprises to actively participate in trading, China's carbon trading pilots have all taken a more realistic approach for getting the allowances distributed through primarily using free distribution with auction and fixed price sale as the supplement. The distribution adopted by the China's pilots is very similar to that of EU ETS and CA CAT in their early phase, which aim at getting more business support and political acceptance. But, at the later phases, the EU and California have both shifted the distribution from free to competitive auction. Although some carbon pilots -- for instance Guangdong, Hubei and Shenzhen -- use auction to distribute allowances, the proportion of auctioned allowances is too small to have any meaningful impacts on the cap-and-trade markets.

Table 2

Allowance distribution in China's carbon trading pilots, EU ETS, and CA CAT

\begin{tabular}{|c|c|c|c|c|c|c|c|c|c|c|c|c|c|}
\hline \multirow{2}{*}{$\begin{array}{c}\text { Distribution } \\
\text { Patterns }\end{array}$} & \multicolumn{7}{|c|}{ China's Carbon Trading Pilots } & \multicolumn{3}{|c|}{ EU ETS } & \multicolumn{3}{|c|}{ CA CAT } \\
\hline & BJ & SH & TJ & SZ & CQ & GD & HB & $\begin{array}{c}\text { Phase } \\
1\end{array}$ & $\begin{array}{c}\text { Phase } \\
2\end{array}$ & $\begin{array}{c}\text { Phase } \\
3\end{array}$ & $\begin{array}{c}\text { Phase } \\
1\end{array}$ & $\begin{array}{c}\text { Phase } \\
2\end{array}$ & $\begin{array}{c}\text { Phase } \\
3\end{array}$ \\
\hline Free & $\geq$ & & & $\leq$ & & $\leq$ & $\geq$ & $\geq$ & $\geq$ & $\leq$ & H: $100 \%$ & H: $100 \%$ & H: $100 \%$ \\
\hline distribution & $95 \%$ & $100 \%$ & $100 \%$ & $95 \%$ & $100 \%$ & $\mathbf{9 7 \%}$ & $90 \%$ & $95 \%$ & $90 \%$ & $50 \%$ & $\begin{array}{l}\text { M:100\% } \\
\text { L:100\% }\end{array}$ & $\begin{array}{l}\text { M:75\% } \\
\text { L:50\% }\end{array}$ & $\begin{array}{l}\text { M:50\% } \\
\text { L:30\% }\end{array}$ \\
\hline $\begin{array}{l}\text { Competitive } \\
\text { auction }\end{array}$ & $\begin{array}{c}< \\
5 \%\end{array}$ & $0 \%$ & $0 \%$ & $\begin{array}{l}\geq \\
3 \%\end{array}$ & $0 \%$ & $\begin{array}{c}\geq \\
3 \%\end{array}$ & $\begin{array}{c}\leq \\
3 \%\end{array}$ & $\begin{array}{c}\leq \\
5 \%\end{array}$ & $\begin{array}{c}\leq \\
10 \%\end{array}$ & $\underset{\mathbf{5 0} \%}{\geq}$ & $\begin{array}{l}\text { H:0\% } \\
\text { M:0\% } \\
\text { L:0\% }\end{array}$ & $\begin{array}{c}\text { H:0\% } \\
\text { M:25\% } \\
\text { L:50\% }\end{array}$ & $\begin{array}{c}\text { H:0\% } \\
\text { M:50\% } \\
\text { L:70\% }\end{array}$ \\
\hline $\begin{array}{l}\text { Fixed price } \\
\text { sale }\end{array}$ & $<$ & $0 \%$ & $0 \%$ & $\begin{array}{c}\geq \\
2 \%\end{array}$ & $0 \%$ & $0 \%$ & $<$ & $0 \%$ & $0 \%$ & $0 \%$ & $\begin{array}{c}\leq \\
1 \%\end{array}$ & $\begin{array}{c}\leq \\
4 \%\end{array}$ & $\begin{array}{c}\leq \\
7 \%\end{array}$ \\
\hline
\end{tabular}

Note: "H" represents high-level risk of carbon leakage, "M" represents middle-level risk of carbon leakage, "L" represents low risk of carbon leakage.

Source: Ecofys (2009), EC (2011, 2012), CARB (2010, 2011), SinoCarbon (2014), and relevant management rules and allocation plans of individual Chinese carbon trading pilots. 
Compared with China where the economy is experiencing a rapid growth, economic growth in the EU and the U.S. is at a much slower pace. With no significant changes in economic output and more reliable emissions data available in EU and California, it is relatively easy to manage allowances in normal situation. However, the unexpected economic crisis in EU has created a large surplus of allowances in its ETS, depressing the clearing price in the trading market, which results in much weaker desire for businesses to reduce carbon emissions. To address this dilemma, the European Commission has taken the "back-loading" of auctions as short-term solution and created a market stability reserve as a long-term measure. The "back-loading" of auctions was implemented through an amendment to the EU ETS Auctioning Regulation, and postponed the auctioning of 900 million allowances planned for 2014-2016 until 2019-2020 [49]. According to the Regulation, the Market Stability Reserve shall be established in 2018 to improve the ETS' resilience to major shocks by adjusting the supply of allowances to be auctioned, and the placing of allowances in the reserve shall operate from 1 January 2019 [50].

In order to maintain production activities in California, the CA CAT adopted the product-based benchmarking approach as shown in Table 1, because the amount of allowances received in the future is dependent on continued California output [31]. The product-based benchmarking, which can utilize product output measurements from data gathered on an ongoing basis, is typically called ex post adjustments to the allocation. Besides, the CA CAT has already created the allowances reserve for strengthening market stability.

\subsubsection{Comparative analysis of the dynamic management of allowances in China's pilots}

In China's carbon trading pilots, a large discrepancy between allocated allowances and enterprises' actual emissions exists due to the fast changes in China's economic output, lack of transparent production information, and incomplete emissions data. It is therefore important for the designers of the China's pilots to develop necessary measures to adjust allowances to prevent enterprises from having a serious shortage or surplus of allowances.

China's carbon trading pilots have thus designed an important mechanism using the ex-post dynamic tune-up feature. For example, in the Hubei pilot, if an enterprise's actual emissions increase or decrease by $20 \%$ from the allocated allowances, the program administrator will add (if actual emissions went up) or take back (if actual emissions decreased) the difference between the actual emissions and the upper or lower $20 \%$ of pre-allocated allowances [43]. Similarly, the Chongqing pilot also includes an ex-post adjustment measure, but the range of upward or downward adjustment is limited to 8\% [35]. For the electricity and heat generation sectors, all the seven pilots have pre-allocated free allowances to enterprises before the compliance period begins, then excessive allowances will be taken back, and shortfall will be made up for covered enterprises when the compliance period ends [27]. In addition, Beijing, Shenzhen, Guangdong, and Hubei pilots have also set up an allowances reserve for adjusting the number of allowances in the market.

To avoid the early problem in EU ETS of flooding the trading market with excessive number of allowances, both CA CAT and China's carbon trading pilots have established certain mechanisms for adjusting and controlling the number of allowances in the market. It is clear that creating some types of ex-post adjustment or dynamic management mechanism could provide great flexibility in dealing with the uncertainty of an emissions trading market.

\section{Challenges facing China's carbon trading pilots and recommendations for addressing these challenges}

There are a number of issues in the design of the carbon allowances in China's carbon trading pilots due to the limited preparation and lack of reliable production and emissions data. These issues become evident after 1-2 years in operation of these pilots. It is important for China to address these issues to meet the country's ambition to create a national carbon trade market in 2017. The following section discusses these issues and provides necessary recommendations for the designers of China's carbon trade programs. . 
China's pilots relies heavily on historical emissions to set up its carbon emissions cap. However, since 2013, China has been experiencing significant economic slowdown and entered into the era of "new normal" in which lower economic growth becomes a typical phenomenon. Fig. 4 shows decreasing GDP growth rates over the past years in the seven carbon trade pilots while Fig. 5 shows a clear downward trend of the production value growth rates of key sectors covered in these pilots. Clearly, cap established based on the prediction of fast economic growth like that in the past Five-Year Plan (2006-2010) is becoming much looser than the current reality under China's economic "new normal."

It is important for China to be careful on determining its carbon cap so that it can avoid the serious problem that EU has faced of allocating too many allowances. In this regard, particular experience in the Hubei pilot worth learning. In addition to the strict control of allowances for existing facilities, the Hubei pilot has also adopted a dynamic adjustment measure to deal with the oversupply of allowances. This measure allows the program administrator to take back the enterprise's allowances surplus resulting from a sharp drop in production, and cancel the allowances in the government reserve and the new entrants reserve which cannot be distributed until the compliance date, and further reduce the total allowances of the next year.

417

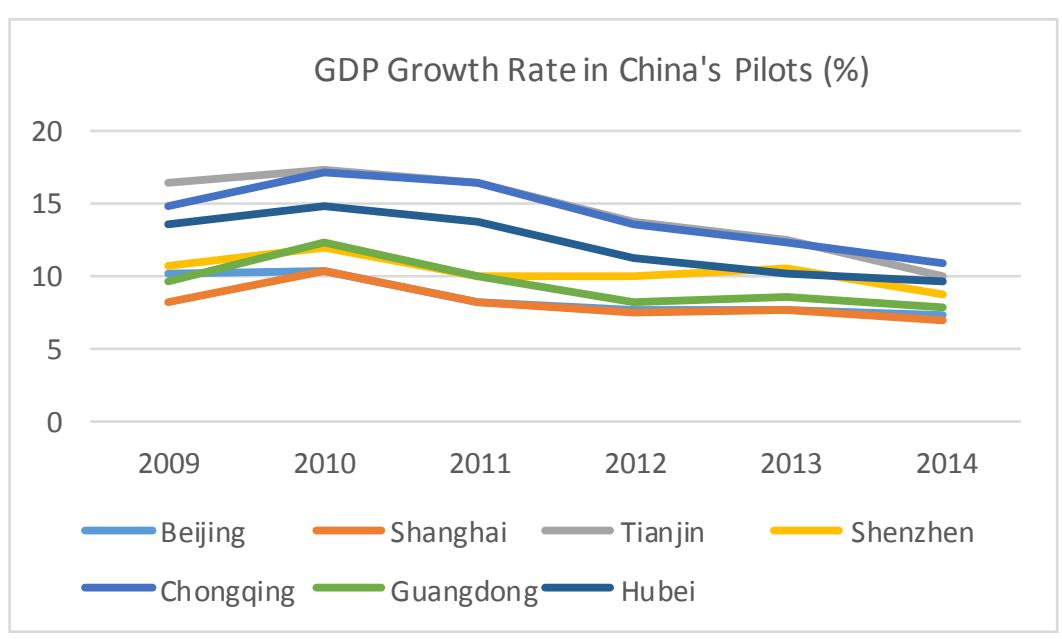

Source: China Statistical Yearbook, and yearly statistical bulletin of China's pilot provinces and cities.

Fig. 4. GDP growth rate tendency in China's carbon trading pilots (2009-2014)

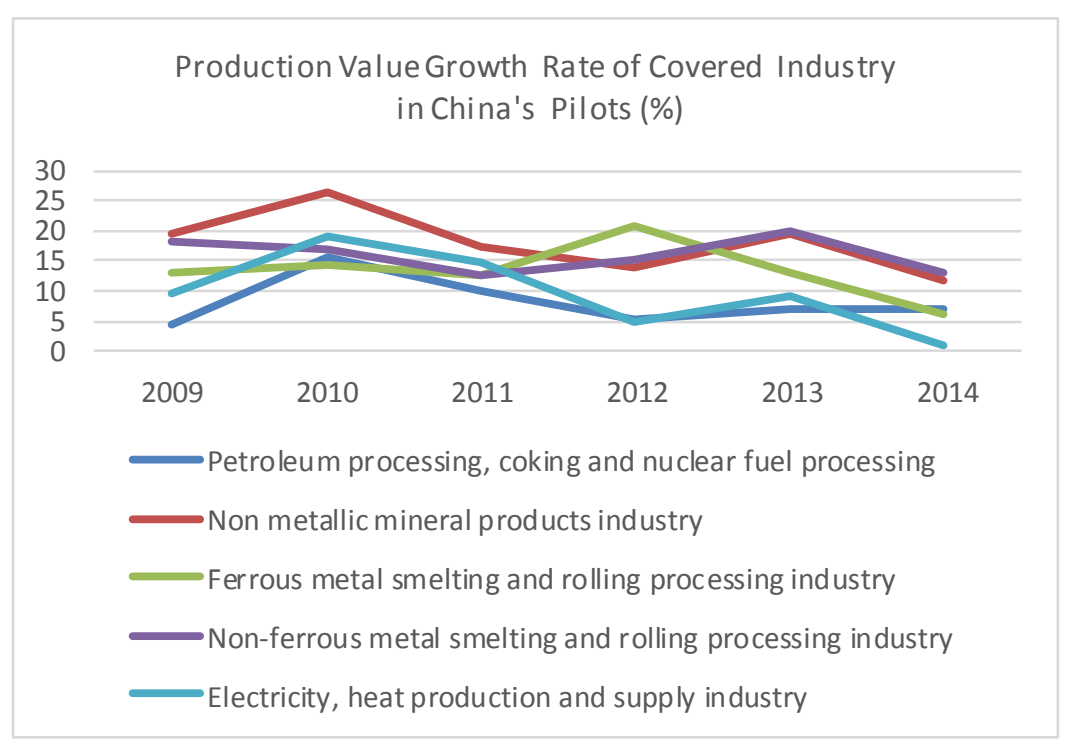

Source: China industrial economy statistical yearbook, and China Industrial statistical yearbook.

Fig. 5. Growth rate tendency of covered industry in China's carbon trading pilots (2009-2014) 
Theoretically, free allocation based on grandfathering will create the unintended consequence of "whipping the fast ox" effect that penalizes the entities that take early actions for reducing carbon emissions. In practice, except for Shanghai and Tianjin, China's current carbon trading pilots mostly use historical emissions without crediting businesses for taking early actions to reduce carbon emissions. This effect will more likely deter businesses from taking serious actions in investing in emission reduction.

To ensure the allocation to be fair and more effective for achieving an optimal reduction of carbon emissions, China should consider of awarding the covered entities for taking actions such as energy efficiency and emission reduction in allowance allocation. Another way to correct the problem resulting from using grandfathering rule is to use an adjustment factor, which is a decreasing function of the covered entity's recent emission growth. And finally, China needs to transform its allocation scheme from the grandfathering rule to the benchmarking approach that more accurately reflects the actual intensity and to award credits for businesses that have taken actions.

\subsection{To solve the problem of double-counting of emissions in the allocation}

For China's carbon trading pilots, double-counting has been recognized as one of the outstanding issues in the allowance allocation. For example, all carbon trading pilots require both consumers and producers of electricity power to get allowances for the power they have consumed or produced. This double-counting of emissions will result in over-supply of allowances, creating negative impacts on the emissions trading scheme [51].

There are two ways to solve this problem. One is for the carbon trading scheme to cover only the direct emission sources, as what EU ETS and CA CAT have done, and exclude indirect emissions on the user side. The other is for the program administrator to divide the responsibility between the source of generation and source of use and allocate allowances according to the shared responsibility among the power producers, distribution companies, and end consumers.

\subsection{To improve the benchmarking method}

Benchmarking has been utilized in China's carbon trading pilots but at quite limited scale and for very few sectors. Moreover, the stringency of the benchmarking method in China's pilots needs to be improved. For instance, according to the different types of generating units, Shanghai and Guangdong pilots have respectively set seven and six emissions benchmark values for power generation according to the installed capacity, and Guangdong pilot has set three benchmark values for cement clinker in accordance with the scale of the production line. It will result in that the benchmark value of production with backward technology and small scale is much higher than that of production with advanced technology and large-scale. In fact, this distorted benchmark approach protects the backward technology and emission-intensive production capacity.

To improve the effectiveness of its carbon trading scheme, China needs to consider shifting the allocation method from grandfathering to benchmarking according to the principle "one product, one benchmark", which is commonly adopted in EU ETS and CA CAT. This change, however, can only be achieved with sufficient and reliable product and business performance data.

\subsection{To increase the proportion of the competitive auction in allowance distribution}

In spite of its importance to reduce the compliance cost of covered entities in the initial phase of a carbon trading scheme, free allocation will lead to reduced efficiency for China's carbon trade pilots and increase abatement cost due to the lack of enterprises' motivation for innovation.. Also, the free allocation cannot provide an effective means for the government to obtain necessary revenue to support public and community programs in reducing carbon emissions and decarbonizing the energy system. Distributing the allowances through competitive auction can make enterprises truly realize the "emissions cost", and fully reflect the principle of "polluter pays". It is, therefore, important for China's carbon trading pilots to start moving away from free distribution and transition to competitive auctioning of allowances at least for leakage-prone industries or certain sectors that are characterized as having overcapacity. 
In China's carbon trade pilots, rules published by the program administrators that govern allowances allocation and distribution lack the necessary clarity and transparency. Most of these rules are described merely in very general terms without specific details [52]. Important information such as what and how various factors are used to determine the allowances have not been provided. However, this type of information is important as it helps covered entities understand the efforts they need to make to reduce their emissions and enables researchers to identify potential flaws in the allowance system design. It will be in China's benefit to strengthen transparency in the design of its allowance allocations and distribution.

In this respect, the EU ETS and CA CAT set good examples. They not only timely publicize their legislative documents involving the allowance mechanism, but also develop a large number of explanatory documents providing the details of the allowances allocation and distribution.

\section{Conclusions}

488

489

490

491

492

493

494

495

496

497

498

499

500

501

502

503

504

\section{5}

506

507

508

509

510

511

512

513

514

515

516

517

518

519

520

521

522

523

524

525

526

527

528

After two years of preparation, China's seven carbon trading pilots officially launched starting in 2013 and 2014. The covered entities in Hubei and Chongqing have completed their first compliance year, while Beijing, Shanghai, Tianjin, Guangdong and Shenzhen pilots have all completed their second compliance year. Drawn upon experiences and lessons learned from the EU ETS and California CAT, China's carbon trading pilots have designed some effective features in allowance allocation and distribution, which include an allowance allocation rule based on historical emissions combined with some benchmarking, a free allowance distribution arrangement combined with some level of auction, and pre-determined quotas combined with ex-post allowance adjustments. There are also some particular issues related to China's carbon trading pilots. The issues regarding the design of the allowance mechanism include over-supply of allowances, lack of allowance credits for businesses that take early abatement actions, double-counting of allowances, a heavy reliance on historical emissions, and lack of clarity and transparency of administrative rules governing the allowances allocation and distribution. China has announced to launch a national carbon trading market. In order to develop a robust and effective a national level carbon trading scheme in China, it is critical for the country to thoroughly assess the problems that have been revealed in the seven carbon trading pilots and carefully identify ways to address these issues.

\section{Acknowledgements}

The authors would like to thank the Oak Foundation for its financial support under the U.S. Department of Energy Contract No. DE-AC02-05CH11231 with the Regent of University of California and thank the China Scholarship Council for supporting Ling Xiong in conducting this joint research. The authors would also like to thank Dai Fan of the California Environmental Protection Agency for her review and valuable comments and thank Rajinder Sahota, David Allgood, and Mary Jane Coombs of California Air Resource Board, Vicky Pollard and Tomas Velghe of Directorate-General for Climate Action of European commission, Christian Ellermann and Alyssa Gilbert of ECOFYS, Tomas Wyns and Erica Jue of CCAP, and Chinese experts including Xiliang Zhang, Maosheng Duan, Dewen Mei, Jing Wang, Zhenqing Sun, Qi Tian, Xiao Lei, Hanwu Liu, Guangxing Yang, Haiou Chen, Aoqian Zang, Qinping Gu, Jin Li, Yijun Chen, Justin Luo, and Zhu Cao for valuable help in answering our questions and providing information.

\section{References}

[1] National Development and Reform Commission (NDRC). Notice on Launching Pilots for Emissions Trading System, 2011.

[2] Sijm, J., Neuhoff K., Chen Y. CO2 cost pass-through and windfall profits in the power sector. Climate Policy, 2006, 6: 49-72.

[3] Benz, E., Löschel A., Sturm B. Auctioning of CO2 emission allowances in Phase 3 of the EU Emissions Trading Scheme. Climate Policy, 2009, 10:705-718.

[4] Pahle, M., Fan L., Schill W. P. How emission certificate allocations distort fossil investments: The German example. Energy Policy, 2011, 39(4): 1975-1987. 
[5] Golombek, R., Kittelsen S. A. C., Rosendahl K. E. Price and welfare effects of emission quota allocation. Energy Economics, 2013, 36: 568-580.

[6] Anderson, B., Di Maria C. Abatement and allocation in the pilot phase of the EU ETS. Environmental and Resource Economics, 2011, 48: 83-103.

[7] Sartor, O., Pallière C., Lecourt S. Benchmark-based allocations in EU ETS Phase 3: an early assessment. Climate Policy, 2014, 14(4):507-524.

[8] Caron, J., Rausch S., Winchester N. Leakage from sub-national climate policy: The case of California's cap-and-trade program. Energy Journal, 2015, 36(2).

[9] Shen B., Dai F., Lu H. California's Cap-and-Trade Programme and Insights for China's Pilot Schemes. Energy \& Environment, 2014, 25(3\&4):551-575.

[10] Zuckerman, J., Laughlin K., Abramskiehn D., Wang X. Cap and Trade in Practice:Barriers and Opportunities for Industrial Emissions Reductions in California. CPI Working Paper, June 2014.

[11] Schmalensee, R., Stavins R. Lessons Learned from Three Decades of Experience with Cap-and-Trade. NBER Working Paper, November 2015, No. 21742.

[12] Han, G., Olsson M., Hallding K., Lunsford D. China's Carbon Emission Trading: An Overview of Current Development. FORSE and Stockholm Environment Institute, Stockholm, 2012.

[13] Lo, Alex Y. Carbon trading in a socialist market economy: Can China make a difference? Ecological Economics, 2013, $87: 72-74$.

[14] Jotzo, F., Löschel A. Emissions trading in China: Emerging experiences and international lessons. Energy Policy, 2014, $75: 3-8$.

[15] Zhang, D., Karplus V.J., Cassisa C., Zhang X.L. Emissions trading in China: Progress and prospects. Energy Policy, 2014, 75:9-16.

[16] Liu, L., Chen C., Zhao Y.i , Zhao E. China's carbon-emissions trading: Overview, challenges and future. Renewable and Sustainable Energy Reviews, 2015, 49:254-266.

[17] Jiang, J.J, Ye B., Ma X. M. The construction of Shenzhen's carbon emission trading scheme. Energy Policy, 2014, 75:17-21.

[18] Wu, L., Qian H., Li J. Advancing the experiment to reality: Perspectives on Shanghai pilot carbon emissions trading scheme, Energy Policy, 2014, 75:22-30.

[19] Liao, Z., Zhu X., Shi J. Case study on initial allocation of Shanghai carbon emission trading based on Shapley value. Journal of Cleaner Production, 2015, 103:338-344.

[20] Qi, S.Z., Wang B.B., Zhang J.H. Policy design of the Hubei ETS pilot in China, Energy Policy, 2014, 75:31-38.

[21] Zhang, Y.J., Wang A.D., Tan W. The impact of China's carbon allowance allocation rules on the product prices and emission reduction behaviors of ETS-covered enterprises. Energy Policy, 2015, 86:176-185.

[22] Tang, L., Wu J., Yu L., Bao Q. Carbon emissions trading scheme exploration in China: A multi-agent-based model. Energy Policy, 2015, 81:152-169.

[23] Zhou, P., Zhang L., Zhou D.Q., Xia W.J. Modeling economic performance of interprovincial CO2 emission reduction quota trading in China. Applied Energy, 2013, 112:1518-1528.

[24] Cui, L.B., Fan Y., Zhu L., Bi Q.H. How will the emissions trading scheme save cost for achieving China's 2020 carbon intensity reduction target? Applied Energy, 2014, 136:1043-1052.

[25] Hong, T., Koo C., Lee S. Benchmarks as a tool for free allocation through comparison with similar projects: Focused on multi-family housing complex. Applied Energy, 2014, 114:663-675.

[26] Xu, J., Yang X., Tao Z. A tripartite equilibrium for carbon emission allowance allocation in the power-supply industry. Energy Policy, 2015, 82:62-80.

[27] Pang, T., Duan M. Cap setting and allowance allocation in China's emissions trading pilot programmes: special issues and innovative solutions. Climate Policy, 2015, published online: 17 Jun 2015.

[28] Ellerman, D. A., Frank J. C., Christian P. Pricing Carbon: The European Union Emissions Trading Scheme. Cambridge University Press, 2010.

[29] European Commission (EC). Preparing the EU's Quantified Emission Limitation or Reduction Objective (QELRO) based on the EU Climate and Energy Package. Commission Staff Working Document, Feb 2012. Available at: http://ec.europa.eu/clima/policies/international/negotiations/docs/swd_13022012_en.pdf

[30] California Air Resource Board (CARB). Overview of ARB Emissions Trading Program. 2011. Available at: http://www.arb.ca.gov/newsrel/2011/cap_trade_overview.pdf

[31] California Air Resources Board (CARB). Cap and Trade Regulation Initial Statement of Reasons (ISOR), Appendix J: Allowance Allocation, 2010. Available at: http://www.arb.ca.gov/regact/2010/capandtrade10/capv4appj.pdf

[32] SinoCarbon. China's carbon market annual report 2013. Jan 2014.

[33] Guangdong DRC. Guangdong Carbon Emission Allowance Allocation Work Plan 2015. Jul 2015.

[34] Hubei DRC. Hubei Carbon Emissions Trading Allowance Allocation Plan 2015. Nov 2015. 
[35] Chongqing DRC. Chongqing Carbon Emissions Allowance Management Rules (Interim). May 2014.

[36] European Commission (EC). Guidance Document $n^{\circ} 2$ on the harmonized free allocation methodology for the EU-ETS post 2012. Jun 2011. Available at: http://ec.europa.eu/clima/policies/ets/cap/allocation/docs/gd2_allocation_methodologies_en.pdf

[37] Lecourt, S., Pallière C., Sartor O. Free allocations in EU ETS Phase 3: The impact of emissions-performance benchmarking for carbon-intensive industry. CDC Climat Research Working Paper n 2013-14, 2013.

[38] Ecofys. Methodology for the free allocation of emission allowances in the EU ETS post 2012. Nov 2009.

[39] Beijing DRC. Beijing Carbon Emissions Trading Pilot Allowance Allocation Methods (Temporary). Nov 2013.

[40] Tianjin DRC. Tianjin Carbon Emissions Trading Allocation Plan to Compliance Enterprises (Temporary). Dec 2013.

[41] Shanghai DRC. Shanghai Carbon Emissions Trading Allowance Allocation and Management Plan (2013-2015). Nov 2013.

[42] Guangdong DRC. Guangdong Carbon Emission Allowance Allocation Work Plan 2013 (Temporary) Notice. Nov 2013.

[43] Hubei DRC. Hubei Carbon Emissions Trading Allowance Allocation Plan 2014. Mar 2014.

[44] Shenzhen Municipal Government. Shenzhen Emissions Trading Management Methods. Mar 2014.

[45] Ye,, B., Jiang J., Miao L., Li J., Peng Y. Innovative Carbon Allowance Allocation Policy for the Shenzhen Emission Trading Scheme in China. Sustainability, 2016, 8(1), 3.

[46] European Commission (EC). Directive 2009/29/EC of the European Parliament and of the Council of 23 April 2009 amending Directive 2003/87/EC so as to improve and extend the greenhouse gas emission allowance trading scheme of the Community. Official Journal of the European Union, 2009, L40: 63-87.

[47] Beijing Municipal Government. Beijing's carbon emissions trading management approach (trial). May 2014.

[48] Hubei Provincial Government. Interim Measures for the administration and trade of carbon emissions in Hubei Province. Apr 2014.

[49] European Commission (EC). COMMISSION REGULATION (EU) No 176/2014 of 25 February 2014 amending Regulation (EU) No 1031/2010 in particular to determine the volumes of greenhouse gas emission allowances to be auctioned in 2013-20. Official Journal of the European Union, 26.2.2014, L56:11-13.

[50] European Commission (EC). Proposal for a DECISION OF THE EUROPEAN PARLIAMENT AND OF THE COUNCIL concerning the establishment and operation of a market stability reserve for the Union greenhouse gas emission trading scheme and amending Directive 2003/87/EC. 2014. Available at: http://ec.europa.eu/clima/policies/ets/reform/docs/com_2014_20_en.pdf

[51] Munnings, C., Morgrnstern R., Wang Z.M., Liu X. Assessing the Design of Three Pilot Programs for Carbon Trading in China. Resources for the Future, Discussion Paper 14-36, Oct 2014.

[52] Wu, Q., Neelis M., Casanova C. Chinese Emission Trading Schemes: Initial Assessment on Allocation. Ecofys Report, Apr 2014.

\section{Appendix 1 \\ Interview questions for experts at the California Air Resource Board}

1. In your view, what are the major differences in CA CAT from EU ETS? Why CA designed its trading scheme differently?

2. Is there a secondary market for CA CAT? Is yes, what the format of that market? Is it regulated and if so by whom?

3. After two years of implementation, what have been the outstanding issues/problems? How CA address these issues?

4. What is the basis and method to determine the emission Cap in California? What are the main factors to consider?

5. From the allowance composition, why CA CAT does not set aside a quota for the California new facility? How to calculate and manage the demand for new facilities quota?

6. In the allowance allocation methodology, from beginning California has completely abandoned the use of the historical emissions and taken comprehensive benchmarking method, is there any misunderstanding and resistance from participating enterprises? How have you communicated with the enterprises?

7. California makes the products benchmark primarily based on the $90 \%$ average carbon intensity of products, why is $90 \%$ rather than the other number?

8. Is there a "double counting" problem in allowance allocation in CA CAT? If not, how to avoid it?

9. For most industrial facilities, in the initial stage allowances are almost freely allocated, but the proportion of free quotas will be based on the extent of the industry's carbon leakage risk, then what is the basis to determine the industry leakage risk is high or low? 
10. California allowance auction design is quite unique, could you introduce how to implement specific quota auction? Such as, on what platform? What entity can participate in? How to use the auction revenue?

11. California has set a reserve price of $\$ 10 /$ ton for quota auction, so what is this based on?

12. CA CAT specially created the quota reserves to stabilize prices and take a fixed price sale in batches way in 2013 to sell its three batches at the price of $\$ 40, \$ 45$ and $\$ 50$, respectively, afterward it will increase at an average annual rate of $5 \%$ adjusted for inflation. Why should CA CAT take a fixed price sale in batches way? What is the basis for the sale prices set at $\$ 40, \$ 45$ and $\$ 50$, and increase at an average annual rate of $5 \%$ ?

13. At three compliance periods, the proportion for quota reserves to stabilize prices are set at $1 \%, 4 \%$ and $7 \%$, respectively, why has been set up like this?

14. In addition to CARB auctions, on what platform California allowances are traded? Does trading take the way of bid matching or transfer agreement? Does CARB allow financial institutions and individuals involved in the transaction? Is there any futures trading?

15. As for the carbon markets link, how will CA CAT e link with Quebec trading market? What are the main difficulties CA is facing in linking CA CAT to other markets? How to overcome these difficulties? In the future, is there links with other carbon markets besides Quebec?

\author{
Appendix 2 \\ Abbreviations Nomenclature \\ 1. GHG -- Greenhouse Gas \\ 2. NDRC -- National Development and Reform Commission \\ 3. DRC -- Development and Reform Commission \\ 4. EU ETS -- European Union Emission Trading System \\ 5. EU -- European Union \\ 6. ETS--Emission Trading System \\ 7. EC-- European Commission \\ 8. NAP -- National Allocation Plan \\ 9. CA CAT -- California's Cap-and-Trade program \\ 10. AB 32-- Assembly Bill 32(California Global Warming Solutions Act of 2006) \\ 11. CARB -- California Air Resource Board \\ 12. CCAP-- Center for Clean Air Policy \\ 13. $\mathrm{MtCO} 2$-- Million Tonnes $\mathrm{CO} 2$ \\ 14. GDP -- Gross Domestic Product
}

